BBA 63365

\title{
Some kinetic aspects of the mechanism of action of an acid phosphatase from baker's yeast (Saccharomyces cerevisiae)
}

As part of a comparative study of the similarities and differences between the two nonspecific phosphomonoesterases (an acid phosphatase (EC 3.I.3.2), pH optimum 3-4, and an alkaline one (EC 3.I.3.I), pH optimum 8-9) of baker's yeast on a molecular level1,2, we have conducted a kinetic investigation of the acid phosphatase.

When only small amounts of a purified enzyme are available, an appropriate method for obtaining information about its mechanism of action is to study the variation of $\mathrm{p} K_{m}, \log V$ and $\log \left(V / K_{m}\right)$ as a function of the $\mathrm{pH}$ according to the procedure of DIXON ${ }^{3}$ and LAIDLER ${ }^{4-6}$. From the shape of the graphs thus obtained, conclusions may be drawn about the $\mathrm{p} K$ of ionizing groups essential for enzymatic activity.

Alvare $Z^{7}$ studied the acid phosphatase of potato in this way, and we have now carried out a similar investigation of the acid yeast phosphatase. As substrates we used $p$-nitrophenyl phosphate, $\beta$-glycerophosphate and $o$-carboxyphenyl phosphate. The latter substrate was chosen because it has also been used by ALBERs, BüsING ANI SCHUDT ${ }^{8}$ in a study of acid yeast phosphatase.

As the enzyme is unstable at $\mathrm{pH}$ values below 3.5 and above 5.5 , we could only conduct this study in the rather narrow $\mathrm{pH}$ range of $3.5-5.5$. All kinetic measurements were performed with dilutions of a single preparation of acid phosphatase, purified as described by BOER AND STEyn-PARVÉ ${ }^{2}$. Both substrate and enzyme were dissolved in o.I $\mathrm{M}$ acetate buffer. When necessary the $\mathrm{pH}$ was adjusted to a suitable value. All experiments were conducted at $30^{\circ}$. In this report one enzyme unit is defined as the amount which will hydrolyze I $\mu$ mole $p$-nitrophenyl phosphate per min in $0 . \mathrm{I} M$ acetate buffer (pH 3.8) at $30^{\circ}$.

Working with $p$-nitrophenyl phosphate the reaction mixture $(0.6 \mathrm{ml}$ containing $0.36-2.16 \mu$ moles $p$-nitrophenyl phosphate per $\mathrm{ml}$ and $2 \cdot \mathrm{I}^{-2}$ enzyme units/ml) was incubated for $5 \mathrm{~min}$ and the reaction stopped by adding $2 \mathrm{ml}$ of $0.5 \mathrm{M} \mathrm{NaOH}$. The absorbance of the $p$-nitrophenol liberated was measured at 4 or m $\mu$. True concentrations of $p$-nitrophenyl phosphate were obtained by acid hydrolysis $\left(3.5 \mathrm{M} \mathrm{H}_{2} \mathrm{SO}_{4}\right.$, $4 \mathrm{~h}, 95^{\circ}$ ), followed by comparison with standard p-nitrophenol solutions.

When $\beta$-glycerophosphate was the substrate, reaction velocities were measured by estimation of $\mathrm{P}_{\mathbf{i}}$ liberated according to the method of TAUssKY AN1) SHORR". The reaction mixture $(0.7 \mathrm{ml})$ contained $0.86-4.30 \mu$ moles $\beta$-glycerophosphate per $\mathrm{ml}$ and $2 \cdot 10^{-1}$ enzyme units $/ \mathrm{ml}$. After incubation $(5 \mathrm{~min})$ the reaction was stopped by adding $3 \mathrm{ml}$ of the acid molybdate-ferrous sulphate solution as described by these authors. The concentration of $\beta$-glycerophosphate was estimated according to the procedure of LEVA AND RAPOPORT ${ }^{10}$.

The reaction of the acid phosphatase with o-carboxyphenyl phosphate was followed in a Beckman DB-Ci spectrophotometer by recording over 3 min the increase of the absorbance at $308 \mathrm{~m} \mu$ as a result of the liberation of salicylic acid. To start the reaction, $50 \mu \mathrm{l}\left(12 \cdot \mathrm{IO}^{-2}\right.$ units) of the enzyme solution were added to $3 \mathrm{ml}$ of the substrate solution (0.2-I.3 $\mu$ moles 0 -carboxyphenyl phosphate per ml). The amount of o-carboxyphenyl phosplate decomposed was calculated from values of the molar 
extinction coefficients of salicylic acid and $o$-carboxyphenyl phosphate, estimated at several pH's. The concentration of $o$-carboxyphenyl phosphate was determined by acid hydrolysis ( $.5 \mathrm{M} \mathrm{HCl}, \mathrm{Ig} \mathrm{h}, 95^{\circ}$ ).

$K_{m}$ (expressed in molarity) and $V$ (calculated as moles substrate per enzyme unit per min) were estimated from initial velocities $\left(v_{\mathbf{i}}\right)$ and substrate concentrations $[S]$ by plotting $v_{i} /[S !$ against $[S]$. The results are shown in the diagrams of Fig. I.

The $\mathrm{p} K_{m}$ for both $p$-nitrophenyl phosphate and $\beta$-glycerophosphate was found to be independent of $\mathrm{pH}$ within the range of measurement $\left(\mathrm{pH} 3.5^{-5} .5\right.$ ). In the case of $p$-nitrophenyl phosphate there is perhaps an indication for a change of slope in the $\mathrm{p} K_{m}-\mathrm{pH}$ plot around $\mathrm{pH} 5.5$ (more evident in the $\log V / K_{m}-\mathrm{pH}$ plot). This is to be expected because $p$-nitrophenyl phosphate has a $K_{2}$ of $5.4-5.5$ (ref. 7 ). The picture for $o$-carboxyphenyl phosphate is quite different from that of the other two substrates. In the $\mathrm{p} K-\mathrm{pH}$ plot, a line with a slope of - I can be drawn through the experimental points. From the measurements obtained for $\log V$ at various $\mathrm{pH}$ values no such curve can be deduced. These results agree with those of ALBERs, BÜSING AND SchUDT ${ }^{8}$.

Relations $p K_{m}, \log V$ and $\log \left(V / K_{m}\right)-p H$

(acid phosphatase)
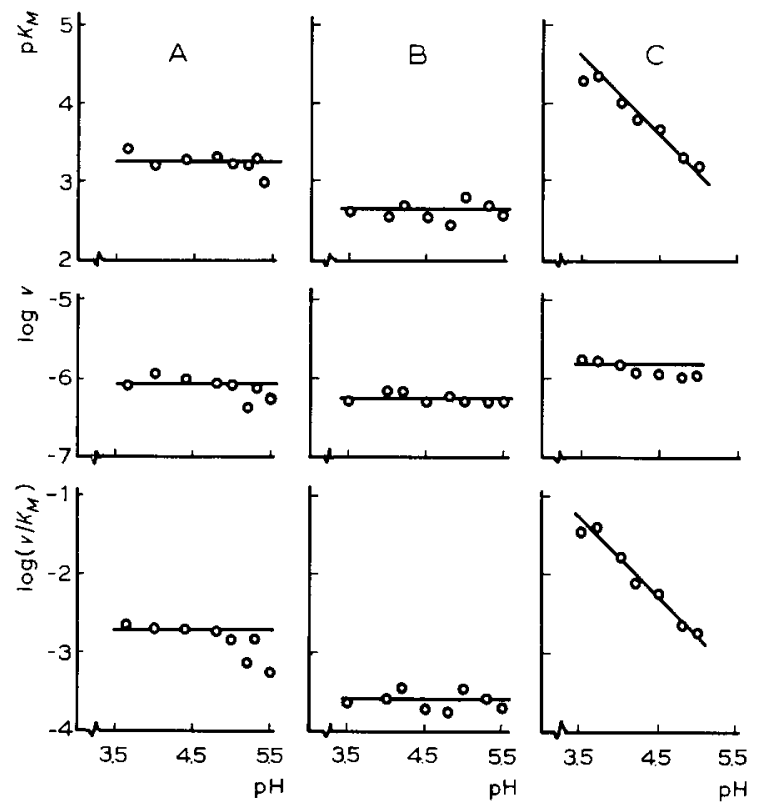

Fig. I. $p K_{\mathbf{m}^{-}}, \log V_{-}, \log \left(V / K_{\mathbf{m}}\right)-\mathrm{pH}$ relations for acid yeast phosphatase at $30^{\circ}$. Substrates: $p-$ nitrophenyl phosphate (A) $\beta$-glycerophosphate (B) and o-carboxyphenyl phosphate (C).

In addition these authors state that the $\mathrm{p} K_{m-} \mathrm{pH}$ plot has a slope of o at $\mathrm{pH}$ values below 3.7. From the point of intersection they conclude that an ionizing group with $\mathrm{p} K 3.87$ is involved and ascribe this $\mathrm{p} K$ to a $\beta$-carboxyl group of an aspartic acid residue in the enzyme. They exclude involvement of the $\mathrm{p} K$ of the carboxyl 
group of the substrate (o-carboxyphenyl phosphate) because, according to WALKER AND $\mathrm{KING}^{11}$, it should have a value of 3.5 .

However, Chanley, Gindler and Sobotka ${ }^{12}$ and Bender and Lawlor ${ }^{13}$ have shown that the $\mathrm{p} K$ of the carboxyl group of $o$-carboxyphenyl phosphate can indeed have values in the range of 3.8-3.9, depending on the ionic strength of the medium.

Bearing this in mind and considering that in our experiments the results with $o$-carboxyphenyl phosphate are different from those obtained with the other two substrates, we conclude that the dependence of $\mathrm{p}_{m}$ on $\mathrm{pH}$ for 0 -carboxyphenyl phosphate must be due to the ionization of the carboxyl group of this substrate and not to the ionization of a carboxyl group in the enzyme.

Our experiments give no indication that there are ionizing groups in the enzyme or in the enzyme-substrate complex with a $\mathrm{p} K$ in the range $3.5-5.5$ essential for activity. In particular the $\beta$-carboxyl group of aspartic acid and the $\gamma$-carboxyl group of glutamic acid can be excluded (see ref. I4).

Naturally other ionizing groups may be involved in the enzymatic activity, but the $\mathrm{p} K$ 's of such groups are situated outside the $\mathrm{pH}$-stability range of the enzyme and so they cannot be detected by this method.

The authors wish to express their thanks to Dr. A. Reinking for helpful discussions.

Laboratory for Physiological Chemistry, P. BoER

The State University, Elizabeth P. Steyn-Parvé

Utrecht (The Netherlands)

I (i. J. M. Tonino and E. I’. Steyn-Parvé, Biochim. Biophys. Acta, 67 (1963) 4.53 .

2 P'. Boer and E. P. Steyn-P'Arvé, Biochim. Biophys. Acta, r 28 (1966) 400.

3 M. Dixon, Biochem. J., 55 (I953) I6r.

4 K. J. Laidler, Trans. Faraday Soc., 5 I (1955) 528.

5 K. J. Laidler, Trans. Faraday Soc., 5 I (19.5) $54^{\circ}$.

6 K. J. LaIDLer, Trans. Faraday Soc., 5 I (I955) 550.

7 E. F. Alvarez, Biochim. Biophys. Acta, 59 (I962) 663.

8 H. Albers, G. Büsing And G. Schudt, Enzymology, 30 (1966) 149.

9 H. H. Taussky and E. Shorr, J. Biol. Chem., 202 (I953) 67.5.

10 E. I. Eva AND S. RAPOPORT, J. Biol. Chem., I 49 (1943) 47.

I I I. S. WalkER and E. J. King, Biochem. J., 47 (1950) 93.

I 2 J. D. Chanley, E. M. Gindler and H. Sobotka, J.Am. Chem. Soc, $7+(1952) 4347$.

13 M. L. Bender and J. M. I.awlor, J. Am. Chem. Soc., 85 (ig63) 3010.

14 Y. Nozaki and Ch. Tanford, J. Biol. Chem., $242(1967) 473$ I.

Received September I 7 th, I968

Biochim. Biophy's. Acta, 171 (1969) 360362 